\title{
Analysis of Multi Minerals from Commercial Juices through Atomic Absorption Spectroscopy and their Role in Human Life
}

\author{
Mehar Ali Kazi \\ Institute of Biochemistry, University of Sindh, Jamshoro, Sindh, Pakistan
}

\begin{abstract}
Now days it has became important to know about juices and their composition regarding mineral content due to their consumption on large scale. The important and popularity of juices related with their nutritional and biological role to healthy life. Different samples of various juices were selected and prepared for their comparative study of analysis of various minerals like copper, lead, calcium, and silver and also to know their importance in human life. These mineral were analyzed by using different reagents at different parameters on Atomic Absorption Spectroscopy.
\end{abstract}

Keywords: Juices, minerals, atomic absorption spectroscopy

\section{Introduction}

Now days it has became important to know about juices and their composition regarding mineral contents due to their consumption on large scale. The importance and popularity of juices is related with their nutritional capabilities, textures and biological role to healthy life $[1,2,3]$.

In hot seasons consumption of liquids especially juices increase to maintain the water and mineral loses during respiration $[4,5]$.

Different fruits are utilized in juices production and these juices are consumed by people to get energy and cope with many challenges like nutrient deficiencies, hot weathers and mineral loses [6].

Human body needs different vitamins to perform various activities required to keep healthy life. Ascorbic acid (vitamin C) present in juices is required to form different structures like collagen, cartilages and blood vessels and also help in iron uptake in human body [7] and vitamin $\mathrm{C}$ also play role of antioxidant phytochemicals which increase blood lipid profile in hyper-cholesterolemia effected patient [8].

Various fruit juices also play the role of detoxification in human body [9]. Fruit juices are also identified most important in the light of their capability to enhance cerium oxidant strength [10].

Recently in different countries of world juices consumption has been increase at large scale in the prevention of reduce risk of different types of tumours [11, 12].

\section{Experimental Work}

\subsection{Digestion and Sample Preparation}

Three (I) different types of juice samples were collected from local market of Hyderabad and analyzed through Atomic Absorption Spectroscopy at Chemical Sciences Research Laboratory, University of Sindh, Jamshoro. These samples belong to "Nestle" company.

- $20 \mathrm{ml}$ of each juice sample was taken in $100 \mathrm{ml}$ of volumetric flask.

- Then $10 \mathrm{ml}$ of $5 \% \mathrm{HCl}$ was added in each juice sample.

- Total volume adjusted up to $100 \mathrm{ml}$ with the help distilled water.

- All samples were kept on centrifuge machine at 4000 rpm for 15 minutes. 
- Then filtered them with the help of filter paper.

- After that filtrate was taken.

- Sample was preserved in bottles.

- Now samples were ready for the analysis on Atomic Absorption Spectroscopy.

- During analysis each sample was compared with standard solution.

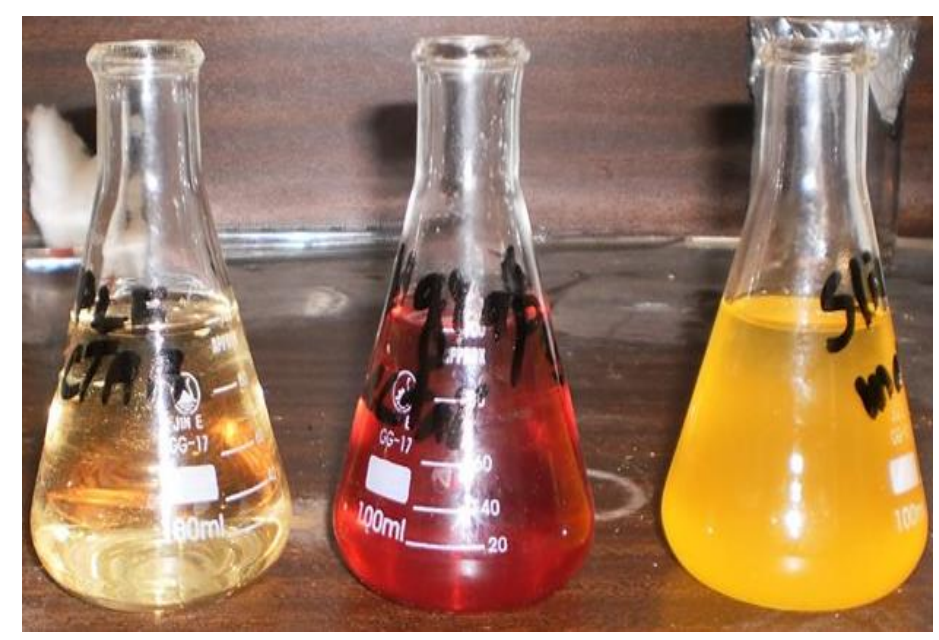

Fig. 1: Sample solution in conical flask.

TABLE I: Quantity for the Digestion of Samples

\begin{tabular}{llll}
\hline \hline S. No & Juice samples & Quantity $(\mathrm{ml})$ & Amount of $\mathrm{HCl}(\mathrm{ml})$ \\
\hline 1 & Mango Slice & 20 & 10 \\
2 & Apple Nectar & 20 & 10 \\
3 & Grapes Nectar & 20 & 10 \\
\hline \hline
\end{tabular}

\section{Results and Discussion}

After the digestion of samples finally for the analysis samples were applied on Atomic Absorption Spectroscopy. Before of the samples run on Atomic Absorption, different parameters of Atomic Absorption Spectroscopy was settled like temperature and pressure. After the settlement of parameters standard of different ppm for every sample was applied. After that different digested samples were applied for analysis of the different minerals. Every sample gave different concentration of minerals one by one. The result obtain after the analysis are given below.

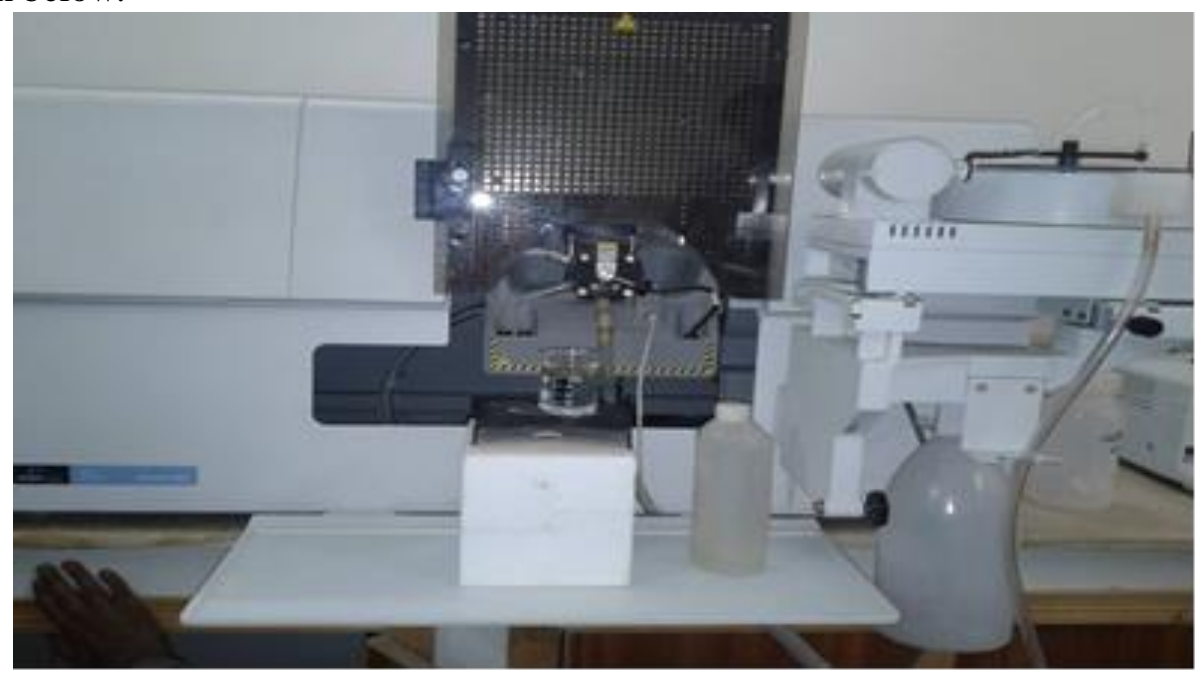

Fig. 2: Atomic Absorption Spectrophotometer. 
TABLE II: Concentration of Copper in ppm (parts per million), $\mathrm{mg} / \mathrm{dl}$ (milli gram per deciliter) and in normal values.

\begin{tabular}{llll}
\hline \hline Juice samples & $\begin{array}{l}\text { Copper } \\
\text { (Result in } \mathrm{mg} / \mathrm{dl})\end{array}$ & $\begin{array}{l}\text { Copper } \\
(\text { Result in ppm) }\end{array}$ & Copper (Result in normal concentration) \\
\hline Mango Slice & $0 \mathrm{mg} / \mathrm{dl}$ & $0 \mathrm{ppm}$ & $0.900 \mathrm{mg} / \mathrm{dl}$ \\
Apple Nector & $0 \mathrm{mg} / \mathrm{dl}$ & $0 \mathrm{ppm}$ & $0.900 \mathrm{mg} / \mathrm{dl}$ \\
Grapes Nector & $0 \mathrm{mg} / \mathrm{dl}$ & $0 \mathrm{ppm}$ & $0.900 \mathrm{mg} / \mathrm{dl}$ \\
\hline \hline
\end{tabular}

Discussion of Table II: This table shows that the concentration of copper in each sample was found to be 0 . Because copper is not present in juices.

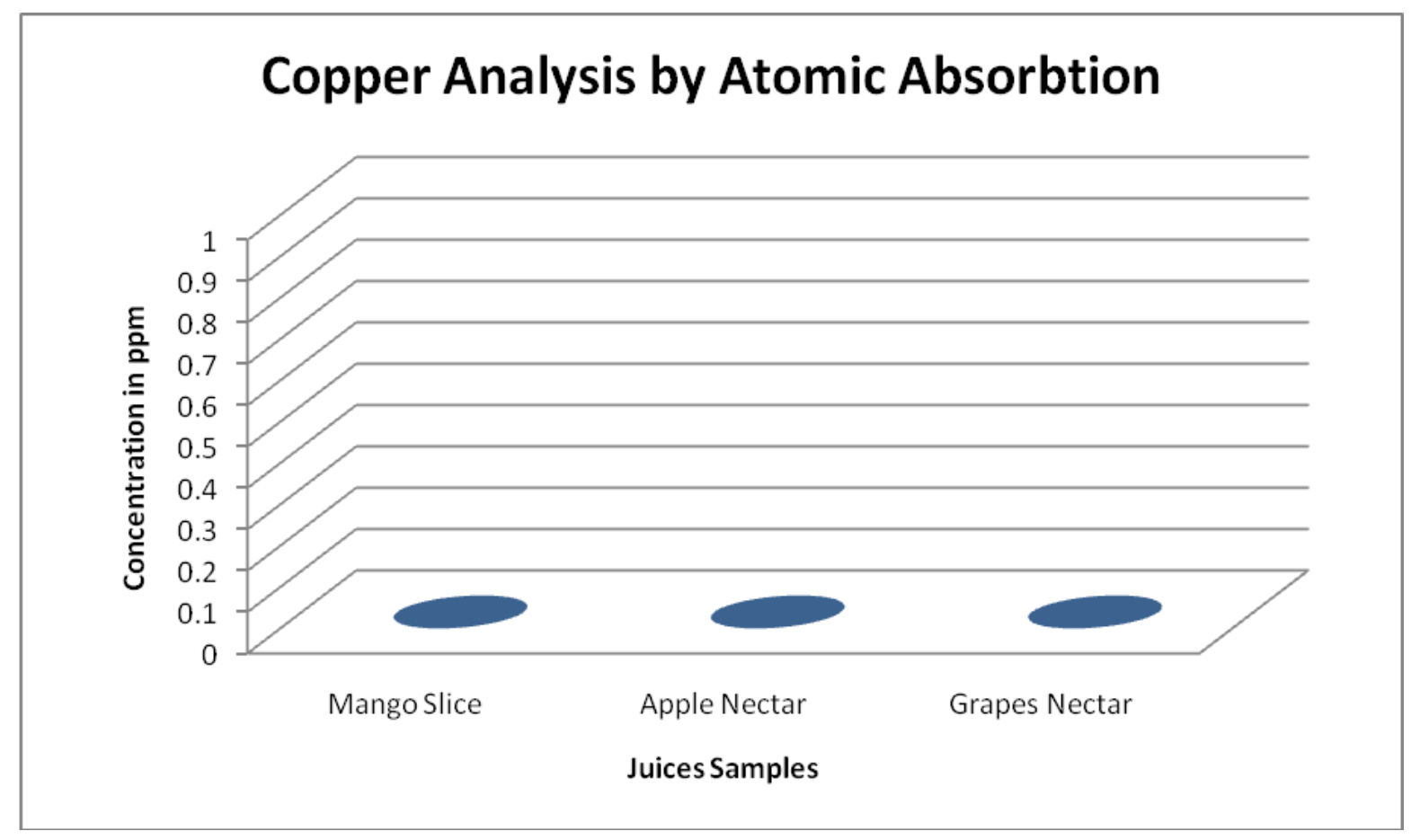

Fig. 3: Concentration of copper in each sample

TABLE III: Concentration of Lead in ppm (parts per million), mg/dl (milligram per liter) and in normal values.

\begin{tabular}{lll}
\hline \hline Juice samples & $\begin{array}{l}\text { Lead } \\
\text { (Result in mg/dl) }\end{array}$ & $\begin{array}{l}\text { Lead } \\
\text { (Result in ppm) }\end{array}$ \\
\hline Mango Slice & $75.5 \mathrm{mg} / \mathrm{l}$ & $0.755 \mathrm{ppm}$ \\
Apple Nector & $80 \mathrm{mg} / \mathrm{l}$ & $0.800 \mathrm{ppm}$ \\
Grapes Nector & $65.4 \mathrm{mg} / \mathrm{l}$ & $0.654 \mathrm{ppm}$ \\
\hline \hline
\end{tabular}

Discussion of Table III: This table shows that concentration of lead in each juice sample (mango slice, apple nectar, grapes nectar) was found to be $0.755 \mathrm{ppm}, 0.8 \mathrm{ppm}$ and 0.654 respectively. 


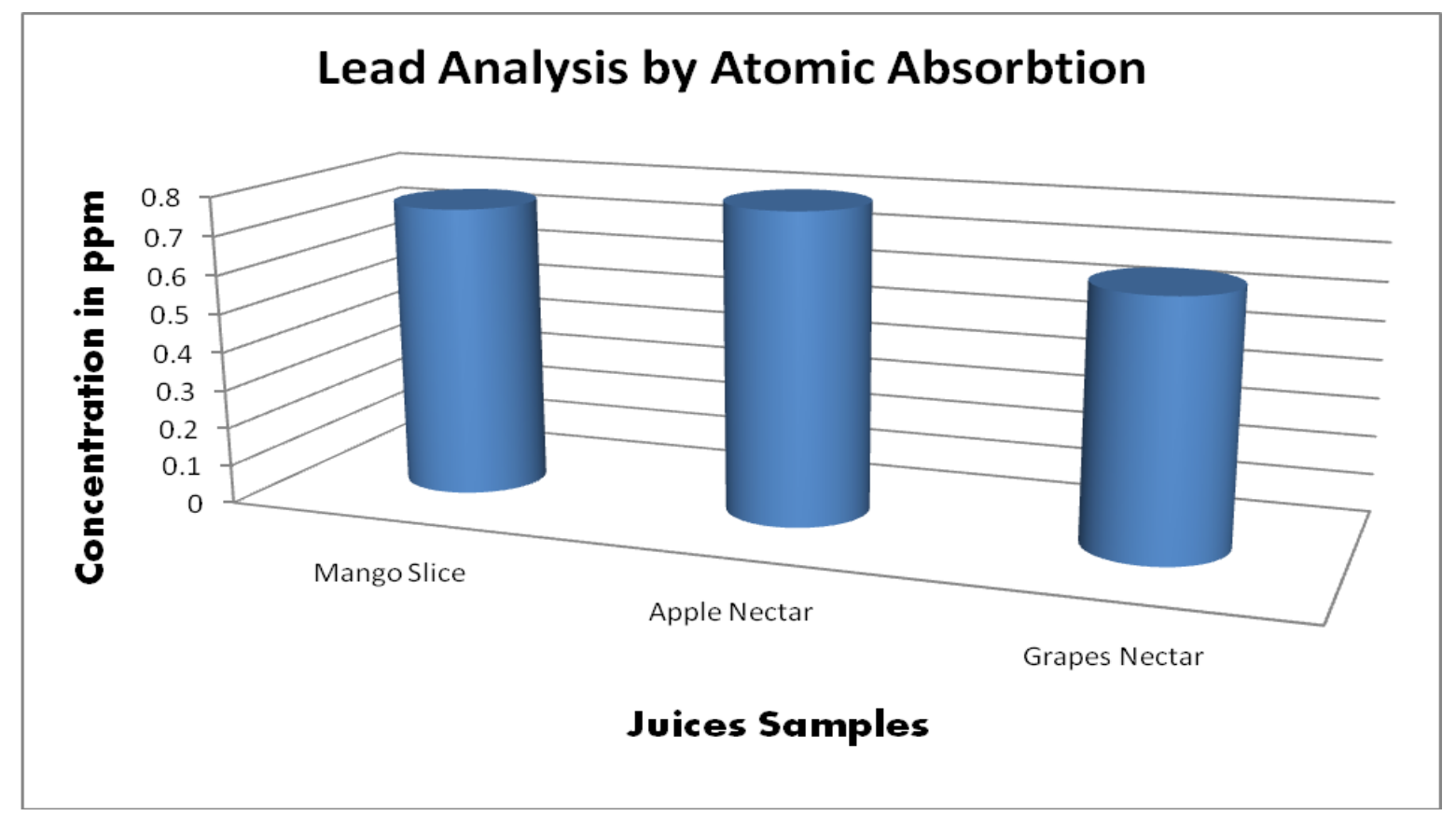

Fig. 4: Concentration of lead in each sample

TABLE IV: Concentration of Copper in ppm (parts per million), $\mathrm{mg} / \mathrm{dl}$ (milli gram per deciliter) and in normal values.

\begin{tabular}{llll}
\hline \hline Juice samples & $\begin{array}{l}\text { Calcium } \\
\text { (Result in mg/dl) }\end{array}$ & $\begin{array}{l}\text { Calcium } \\
\text { (Result in ppm) }\end{array}$ & $\begin{array}{l}\text { Calcium } \\
\text { (Result in normal concentration) }\end{array}$ \\
\hline Mango Slice & $2470 \mathrm{mg} / \mathrm{l}$ & $24.7 \mathrm{ppm}$ & $1300 \mathrm{mg} / \mathrm{dl}$ \\
Apple Nector & $1890 \mathrm{mg} / \mathrm{l}$ & $18.9 \mathrm{ppm}$ & $1300 \mathrm{mg} / \mathrm{dl}$ \\
Grapes Nector & $990 \mathrm{mg} / \mathrm{l}$ & $9.9 \mathrm{ppm}$ & $1300 \mathrm{mg} / \mathrm{dl}$ \\
\hline \hline
\end{tabular}

Discussion of Table IV: This table shows that concentration of Calcium in each juice sample (mango slice, apple nectar, grapes nectar) was found to be $24.7 \mathrm{ppm}, 18.9 \mathrm{ppm}, 9.9 \mathrm{ppm}$ respectively.

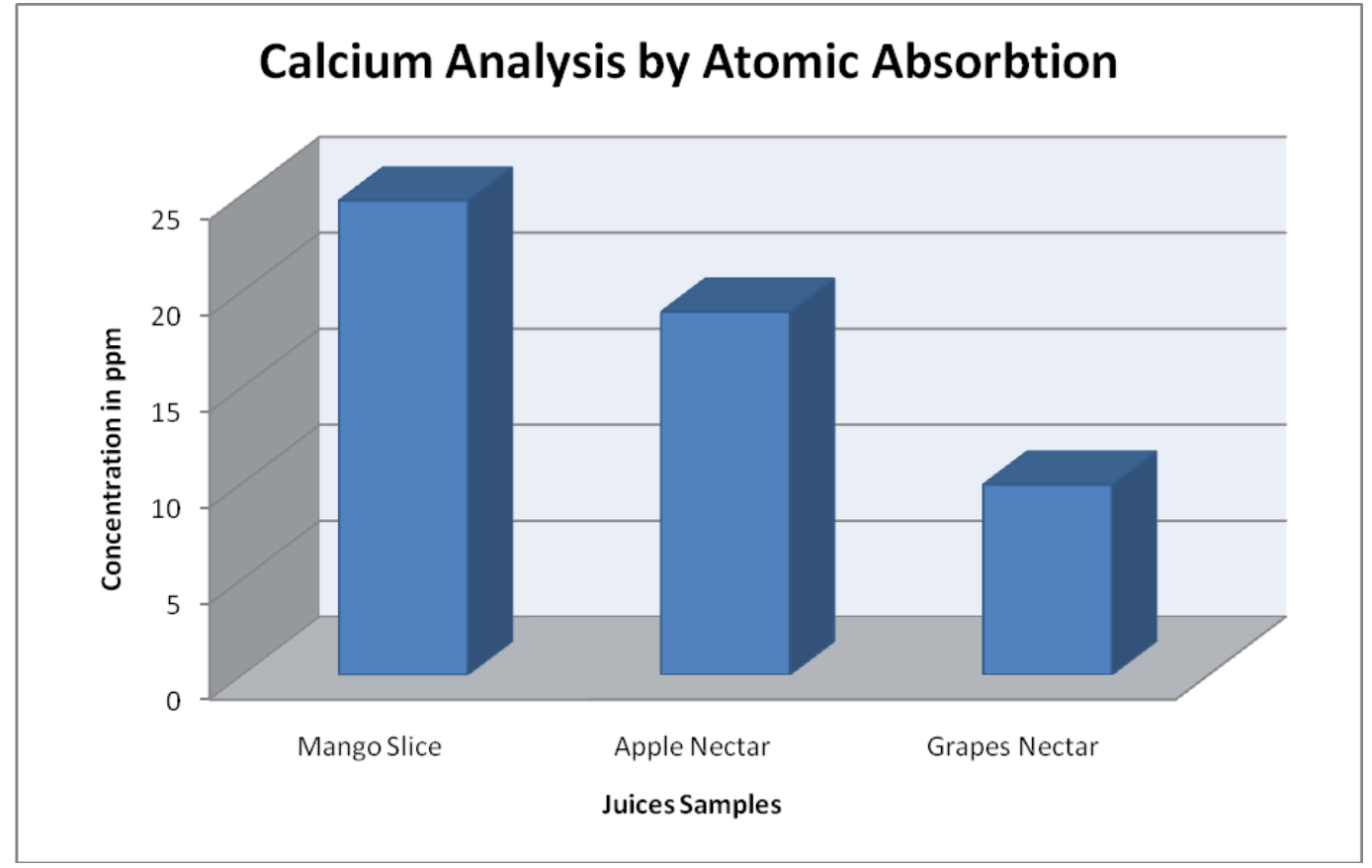

Fig. 5: Concentration of Calcium in each sample 
TABLE V: Concentration of Lead in ppm (parts per million), $\mathrm{mg} / \mathrm{dl}$ (milligram per liter) and in normal values.

\begin{tabular}{lll}
\hline \hline Juice samples & $\begin{array}{l}\text { Silver } \\
(\text { Result in } \mathrm{mg} / \mathrm{dl})\end{array}$ & $\begin{array}{l}\text { Silver } \\
(\text { Result in } \mathrm{ppm})\end{array}$ \\
\hline Mango Slice & No detected & No detected \\
Apple Nector & No detected & No detected \\
Grapes Nector & No detected & No detected \\
\hline \hline
\end{tabular}

Discussion of Table V: This table shows that concentration of Silver in each juice sample (mango slice, apple nectar, grapes nectar) was not detected.

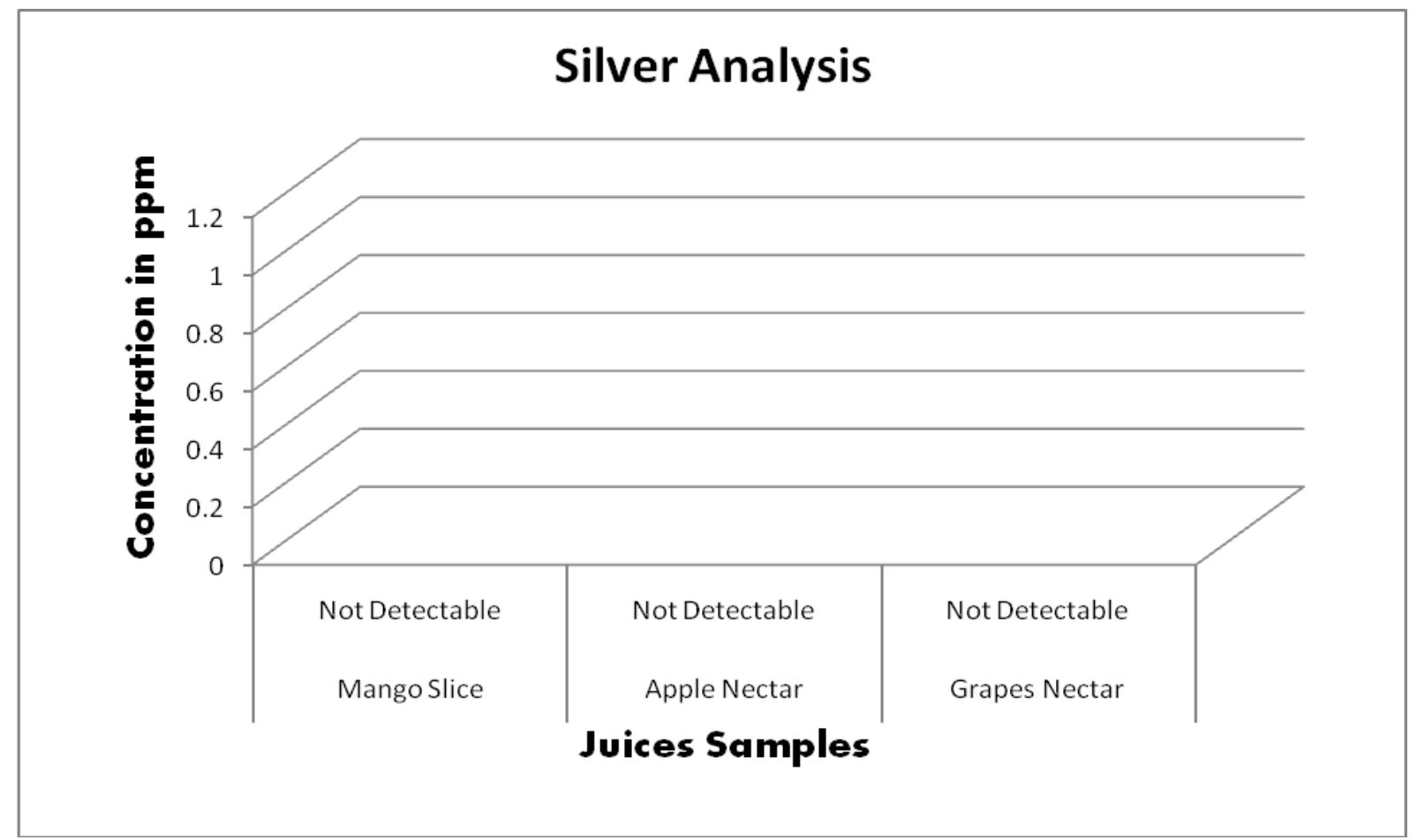

Fig. 6: Concentration of silver in each sample

\section{Conclusion}

The findings of this research study clarified that the analyzed samples of fruit juices are best source of minerals. Minerals that play an important role in maintaining fruit quality and determining a fruit's nutritive value are a natural component of many fruits. The chemical composition of the fruit and the juice differs depending on the cultivar, the growing region, the climate, the fruit's maturity, cultural practices and manufacturing systems. There is rather limited data on the nutrition information, particularly with regard to the mineral constituents, of $100 \%$ juices and itheir role in human health. Therefore, knowledge about the mineral nutrients in commercial juices appears to be necessary to understand the quality, authenticity and potential safety risks of the juice. This work indicates that Calcium is highly present in Mango slice sample i.e 24.7 ppm rather than in other juice samples. Whereas copper and silver not were detect. Heavy metals content in commercial fruit juices (apple, mango and grapes) are also present on market. The highest content of Lead was found in apple juices. The obtained content of heavy metals and minerals in fruit juices is due to the concentration of these elements in raw materials and also are influenced by the manufacturing process. The metal concentration in raw materials depend on a number of factors, including the soil composition, the external conditions during fruit growing and fruit harvesting. As final conclusion, the fruits juices are good nutritive products, being natural products with important concentration of some micronutrients and water. If the sanitation conditions are complied, then fresh fruit juices should be a part of everyone's diet, as healthy diet habits. 


\section{References}

[1] A. Akpınar-Bayızit, "Analysis of mineral content in pomegranate juice by ICP-OES", Asian Journal of Chemistry, vol. 22(8), pp. 6542-6546. 2010.

[2] N. Jalbani, F. Ahmed, U. Rashid, A. B. Munshi, and A. Kandhro, "Determination of essential elements (Cu, Fe and Zn) in juices of commercially available in Pakistan". Food and Chemical Toxicology, vol. 48(10), pp. 2737-2740, 2010. https://doi.org/10.1016/j.fct.2010.06.048

[3] I. J. Cindrić, M. Zeiner, M. Kröppl, and G. Stingeder, "Comparison of sample preparation methods for the ICP-AES determination of minor and major elements in clarified apple juices", Microchemical journal, vol. 99(2), pp. 364-369, 2011.

https://doi.org/10.1016/j.microc.2011.06.007

[4] J. H. Al-Jedah, and R. K. Robinson, "Nutritional value and microbiological safety of fresh fruit juices sold through retail outlets in Qatar", Pakistan Journal of Nutrition, vol. 1(2), pp. 79-81, 2002.

https://doi.org/10.3923/pjn.2002.79.81

[5] B. Victor, M. Peter, and Z. Lourdes, "Trace element in fruit juice", Academic J, vol. 146(2), 256, 2012.

[6] N. M. Nnam, and I. E. Njoku, "Production and evaluation of nutrient and sensory properties of juices made from citrus fruits", Nigerian Journal of Nutrition Science, vol. 26(2), 62-66, 2005.

[7] A. A. Franke, R. V. Cooney, S. M. Henning, and L. J. Custer, "Bioavailability and antioxidant effects of orange juice components in humans", Journal of agricultural and food chemistry, vol. 53(13), 5170-5178, 2005. https://doi.org/10.1021/jf050054y

[8] E. M. Kurowska, J. D. Spence, J. Jordan, S. Wetmore, D. J. Freeman, L. A. Piché, and P. Serratore, "HDL-cholesterolraising effect of orange juice in subjects with hypercholesterolemia", The American journal of clinical nutrition, vol. 72(5), pp. 1095-1100, 2000.

[9] D. M. Minich, and J. S. Bland, "Acid-alkaline balance: role in chronic disease and detoxification", Alternative therapies in health and medicine, vol. 13(4), 62, 2007.

[10] H. Ghanim, C. L. Sia, M. Upadhyay, K. Korzeniewski, P. Viswanathan, S. Abuaysheh, Mohanty, P. and P. Dandona, "Orange juice neutralizes the proinflammatory effect of a high-fat, high-carbohydrate meal and prevents endotoxin increase and Toll-like receptor expression”, The American journal of clinical nutrition, vol. 91(4), pp. 940-949, 2010.

https://doi.org/10.3945/ajcn.2009.28584

[11] K. E. Brock, G. Berry, P. A. Mock, R. MacLennan, A. S. Truswell, and L. A. Brinton, "Nutrients in diet and plasma and risk of in situ cervical cancer", Journal of the National Cancer Institute, vol. 80(8), 580-585, 1988.

https://doi.org/10.1093/jnci/80.8.580

[12] M. L. Kwan, G. Block, S. Selvin, S. Month, and P. A. Buffler, "Food consumption by children and the risk of childhood acute leukemia", American journal of epidemiology, vol. 160(11), pp. 1098-1107, 2004.

https://doi.org/10.1093/aje/kwh317 